\title{
Effects of the carbon nanotube and polymer amounts on ultrafiltration membranes
}

\author{
Evrim Celik Madenli ${ }^{{ }^{\dagger}}$, Zeliha Ilkay Ciftci $^{2}$ \\ ${ }^{1}$ Department of Environmental Engineering, Suleyman Demirel University, 32260 Isparta, Turkey \\ ${ }^{2}$ Provincial Directorate of Environment and Urbanization Ministry, Governorship of Burdur, 15100, Burdur, Turkey
}

\begin{abstract}
Composite membranes with nano-sized inorganic materials have high selectivity, high hydrophilicity, and improved fouling resistance. Blending Carbon Nanotubes (CNTs) in the polymer solution improves membrane properties like hydrophilicity, water permeability, selectivity, and fouling resistance. The effect of the polymer amount, together with the CNT amount in the polymer solution on membrane properties, was investigated in this work. There was more than $10 \%$ increase in the hydrophilicity of the membranes with $1 \%$ CNT addition, but it was not altered with the polymer amount. The porosity was increased almost $30 \%$ by $1 \%$ CNT addition in membranes prepared by $10 \%$ and $12 \%$ polymer concentration (P-10:C-0 and P-12:C-0), but only 16\% increase in porosity occurred in membrane prepared by $15 \%$ polymer concentration (P-15:C-0). The flux of the P-15:C-0 membrane was increased four times by $1 \%$ CNT addition. Besides, fouling resistance of the membranes decreased with increasing polymer amount but increased with increasing CNT amount. BSA rejection increased with increasing polymer amount or CNT amount in the polymer solution. Hence membranes prepared with a higher amount of polymer are more prone to membrane property improvements with CNT addition. The increase in flux and selectivity by CNT addition in all membranes prepared with different polymer concentrations will increase the membrane life-time and reduce the treatment cost.
\end{abstract}

Keywords: Carbon Nanotubes, Fouling Resistance, Ultrafiltration, Polyethersulfone

\section{Introduction}

Ultrafiltration can be considered as a porous membrane. The pore size of the ultrafiltration membranes typically ranges from 0.001 $\mu \mathrm{m}$ to $0.1 \mu \mathrm{m}$ [1]. The structure of the ultrafiltration membranes is generally anisotropic, with a dense layer above the microporous layer. Separation is performed on the dense layer, and mechanical strength is provided by the microporous layer [2]. Although small suspended particles and dissolved macromolecules pass through the ultrafiltration membrane, bigger molecules are mainly rejected [3].

While polymeric membranes are flexible, tough, cheap, and have good separation properties, their mechanical, thermal, and chemical resistance are low. Besides, their fouling resistance is low due to their hydrophobic nature. Therefore, hybrid membranes made of organic and inorganic constituents draw attention. These membranes are expected to have a membrane forming property of the organic constituent and the physicochemical properties of the in- organic constituent [4]. Composite membranes with inorganic nanomaterials are noted for their improved properties, such as enhanced fouling resistance, selectivity, and hydrophilicity $[5,6]$.

Carbon nanotubes (CNTs) developed by Iijima in 1991 [7], have exceptional properties such as high aspect ratio, high mechanical and chemical stability, and high electrical conductivity [8]. The electrical, physical, chemical, and structural properties of CNTs have made them attractive candidates for new technologies for overcoming water scarcity and water pollution issues. CNT-based nanomaterials have been used as sorbents, catalysts, etc., in water treatment [9-12]. Pure CNTs are held together as clusters in polymer solution during membrane fabrication and considerably reduce permeability and the selectivity of the fabricated membranes. In addition, CNTs are hydrophobic and insoluble in most solvents. Because of these properties of the pure CNTs, functionalization is carried out. Positive $\left(-\mathrm{NH}_{3}{ }^{+}\right)$, negative (-COO), or hydrophobic (aromatic rings) groups can be added to CNT surfaces with functionalization [13, 14]. CNT blended polymeric membranes exhibit high
This is an Open Access article distributed under the terms of the Creative Commons Attribution Non-Commercial License (http://creativecommons.org/licenses/by-nc/3.0/) which permits unrestricted non-commercial use, distribution, and reproduction in any medium, provided the original work is properly cited.

Copyright (C) 2022 Korean Society of Environmental Engineers
Received November 19, 2020 Accepted June 02, 2021

${ }^{\dagger}$ Corresponding author

E-mail: evrimcelik@sdu.edu.tr

Tel: +90 2462111691 Fax: +90 2462111072

ORCID: 0000-0003-1806-9121 
permeability, high thermal stability, improved mechanical strength, and high fouling resistance [15].

Choi et al. [16] and Qiu et al. [17] showed that morphology and the permeation properties of the composite membranes depend on the CNT amount by preparing polysulfone (PSU)/CNT composite membranes. Nechifor et al. [18] showed the successful removal of lead and mercury by PSU/CNT composite membranes. Celik et al. $[19,20]$ synthesized polyethersulfone (PES)/CNT composite membranes, which showed improved protein adsorption and higher fouling resistance. Zhao et al. [21] and Kim et al. [22] demonstrated the improved salt rejection performance and fouling resistance of the polyamide/CNT composite membranes. Wang et al. [23] prepared PES/CNT composite membranes for nanofiltration, which showed higher flux and salt rejection. Yang et al. [24] and Celik Madenli et al. [25] proved the improved antibacterial efficiency and suppressed biofilm growth of the PES/CNT composite membranes.

To date, several authors have shown the enhanced membrane properties like hydrophilicity, permeability, selectivity, and fouling and biofouling resistance by blending CNTs [16-29]. However, there have been no reports on the comparison of the membranes prepared in different polymer and CNT concentrations. This work aims to examine the effect of the polymer amount together with the CNT amount in the polymer solution on membrane properties. Membranes were prepared with different polymer and CNT concentrations to determine the effects of polymer and CNT amount in the polymer solution. To subsequently characterize the CNTs and fabricated membranes, water contact angle, pure water flux, permeation tests, Fourier transform infrared (FTIR) spectroscopy, and transmission electron microscopy (TEM) were used.

\section{Materials and Methods}

\subsection{CNT Functionalization and Characterization}

CNTs were functionalized in an acid mixture, as described elsewhere [27]. In brief, CNTs (Nanostructured and Amorphous Materials Inc., USA) were ultrasonicated at $70^{\circ} \mathrm{C}$ for $9 \mathrm{~h}$ in $3: 1$ (v/v) $\quad \mathrm{HNO}_{3} \quad$ (70\%; Sigma-Aldrich, USA): $\mathrm{H}_{2} \mathrm{SO}_{4} \quad$ (95-98\%; Sigma-Aldrich, USA) mixture. After the acid treatment, CNTs were washed until a neutral $\mathrm{pH}$ and dried at $100^{\circ} \mathrm{C}$ overnight. The interaction mechanism is shown in Fig. 1.

The surface functional groups of nanotubes were detected by FTIR (Spectrum Two, PerkinElmer, USA), comprising a $\mathrm{LiTaO}_{3} \mathrm{MIR}$ detector with a germanium crystal plate. Infrared spectra were recorded in the frequency range of 4,000-400 $\mathrm{cm}^{-1}$ with the resolution of $0.5 \mathrm{~cm}^{-1}$. The morphology of the raw and functionalized CNTs were analyzed by TEM (G2 F20; FEI Tecnai, USA). TEM samples were prepared by dropping suspension of CNTs in isopropyl alcohol on the copper grid with carbon film.

\subsection{Membrane Fabrication and Characterization}

Membranes were fabricated as described in our previous publications [19, 20]. In short, membrane solutions were prepared by ultrasonicating functionalized CNTs in 1:9 (v/v) n-methyl2-pyrrolidinone (NMP, anhydrous 99.5\%; Sigma-Aldrich, USA):N,N- Dimethylformamide (DMF, anhydrous 99.5\%; Sigma-Aldrich, USA) mixture and dissolving PES (Veradel 3000P; Solvay Specialty Polymers, Germany). The prepared membrane solution was ultrasonicated and then cast by using a casting knife and a film applicator (1133N, Sheen, USA). Cast membrane solution was directly immersed into a coagulation bath. The schematic fabrication process of the membranes is presented in Fig. 1. Note that the membranes marked as P-10:C-0.5 refer to membranes prepared in a polymer solution in which the amount of PES was $10 \%$, and the amount of CNTs with respect to PES was $0.5 \%$ by weight.

The contact angle goniometer (T200, KSV, USA) was used to measure the contact angles. The reported water contact angles were the average of at least seven measurements for each membrane. A one-way ANOVA test was applied $(\mathrm{p}<0.05)$ to the results of contact angle measurements. The overall porosity $(\varepsilon)$ of the membranes was calculated by using Eq. (1) [30, 31]:

$$
\varepsilon=\frac{W_{w}-W_{d}}{\rho_{w} \times A \times h}
$$

where $\mathrm{h}$ is the membrane thickness $(\mathrm{cm}), \mathrm{A}$ is the effective membrane area $\left(\mathrm{cm}^{2}\right), \rho_{\mathrm{w}}$ is the water density $\left(0.9978 \mathrm{~g} / \mathrm{cm}^{3}\right.$ at $\left.22^{\circ} \mathrm{C}\right)$, and $\mathrm{W}_{\mathrm{w}}$ and $\mathrm{W}_{\mathrm{d}}$ are the weight of the wet and dry membranes (g), respectively. The porosity data are the average value of at least two measurements for each membrane. The mean pore diameters of membranes $\left(\mathrm{r}_{\mathrm{m}}, \mu \mathrm{m}\right)$ were determined by filtration velocity method according to Eq. (2) (Guerout-Elford-Ferry equation) $[30,32]$ :

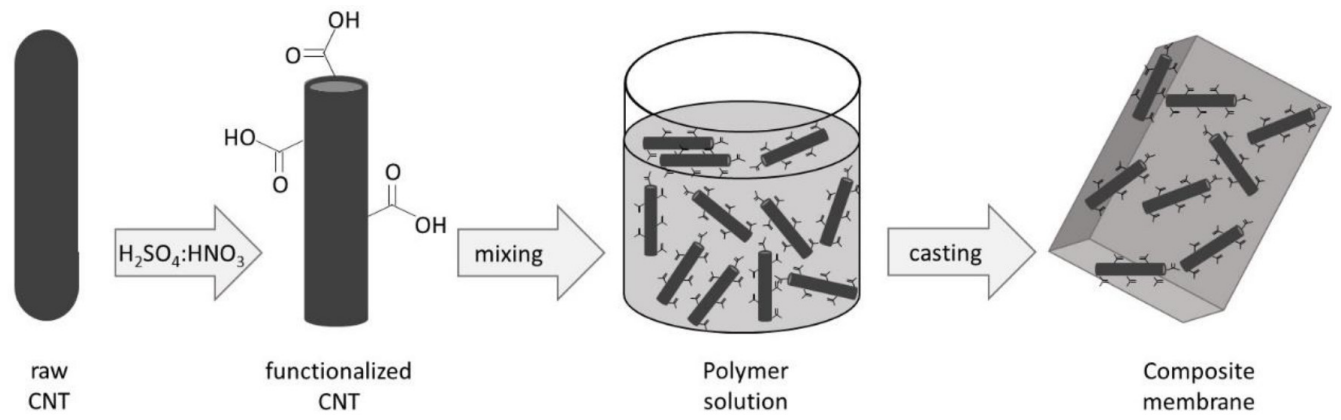

Fig. 1. Schematic representation of CNT functionalization and membrane fabrication. 


$$
r_{m}=\sqrt{\frac{(2.9-1.75 \varepsilon) \times 8 \times \mu \times h \times Q}{\varepsilon \times A \times \Delta P}} \times 10^{4}
$$

where $\mu$ is water viscosity $\left(9.544 \times 10^{-4} \mathrm{~Pa}\right.$-s at $\left.22^{\circ} \mathrm{C}\right), \mathrm{Q}$ is the flowrate $\left(\mathrm{cm}^{3} / \mathrm{s}\right)$, and $\Delta \mathrm{P}$ is the trans-membrane pressure $(\mathrm{Pa})$.

\subsection{Membrane Permeability and Selectivity}

A dead-end membrane test unit (HP4750, Sterlitech, USA) with $14.66 \mathrm{~cm}^{2}$ of effective membrane area was used during the permeability and selectivity tests. The pressure source of the test unit was compressed air. 0.5 bar of constant transmembrane pressure was applied during permeability and selectivity tests. The water flux $\left(\mathrm{J}_{\mathrm{w}}\right)$ and hydraulic resistance of the membranes $\left(\mathrm{R}_{\mathrm{vm}}, \mathrm{m}^{-1}\right)$ were determined by using Eq. (3).

$$
J_{w}=\frac{V}{A \Delta t}=\frac{\Delta P}{\mu R_{v m}}
$$

where $\mathrm{V}$ is the volume of the permeate $(\mathrm{L})$, and $\Delta \mathrm{t}$ is time (h).

Bovine serum albumin (BSA, $1 \mathrm{~g} / \mathrm{L}$ ) filtration for $1 \mathrm{~h}$ was performed to examine the selectivity and fouling resistance. The protein flux $\left(\mathrm{J}_{\mathrm{p}}\right)$ after $1 \mathrm{~h}$ of BSA filtration and BSA rejection ratio $(\mathrm{R}$, $\%)$ was determined by using Eq. (4) and Eq. (5), respectively.

$$
\begin{aligned}
& J_{p}=\frac{V}{A \Delta t}=\frac{\Delta P}{\mu R_{f m}} \\
& R=\frac{C_{f}-C_{p}}{C_{f}} \times 100
\end{aligned}
$$

where $R_{f m}\left(m^{-1}\right)$ is the fouled membrane's hydraulic resistance, and $\mathrm{C}_{\mathrm{p}}(\mathrm{mg} / \mathrm{L})$ and $\mathrm{C}_{\mathrm{f}}(\mathrm{mg} / \mathrm{L})$ are the BSA concentration of the permeate and feed solutions, respectively [28]. The molecular weight of BSA is approximately $68 \mathrm{kDa}$, and the molecular size is $14 \mathrm{~nm} \times 4 \mathrm{~nm} \times 4 \mathrm{~nm}$ [33].

\section{Results and Discussion}

\subsection{CNT Functionalization and Characterization}

CNTs aggregate because of strong van der Waals interactions to each other [34]. Besides, CNTs are chemically inert and insoluble in water or organic solvents [35]. The exceptional properties of the CNTs can be combined with other components by enhancing their solubility and processability through functionalization. CNTs can be functionalized by nitric acid, sulfuric acid, or mixtures of both. Functionalization introduces defects on the nanotube surface, cuts and shortens the CNTs, and opens the tips of the CNTs. The functionalization of CNTs introduces oxygen-containing groups at the tips and defect sites [36].

Fig. 2 shows the TEM images of the CNTs. While raw CNTs were $0.2-30 \mu \mathrm{m}$, functionalized CNTs were $50-500 \mathrm{~nm}$. In addition, most of the raw CNTs had closed tips, yet functionalization opened their tips.
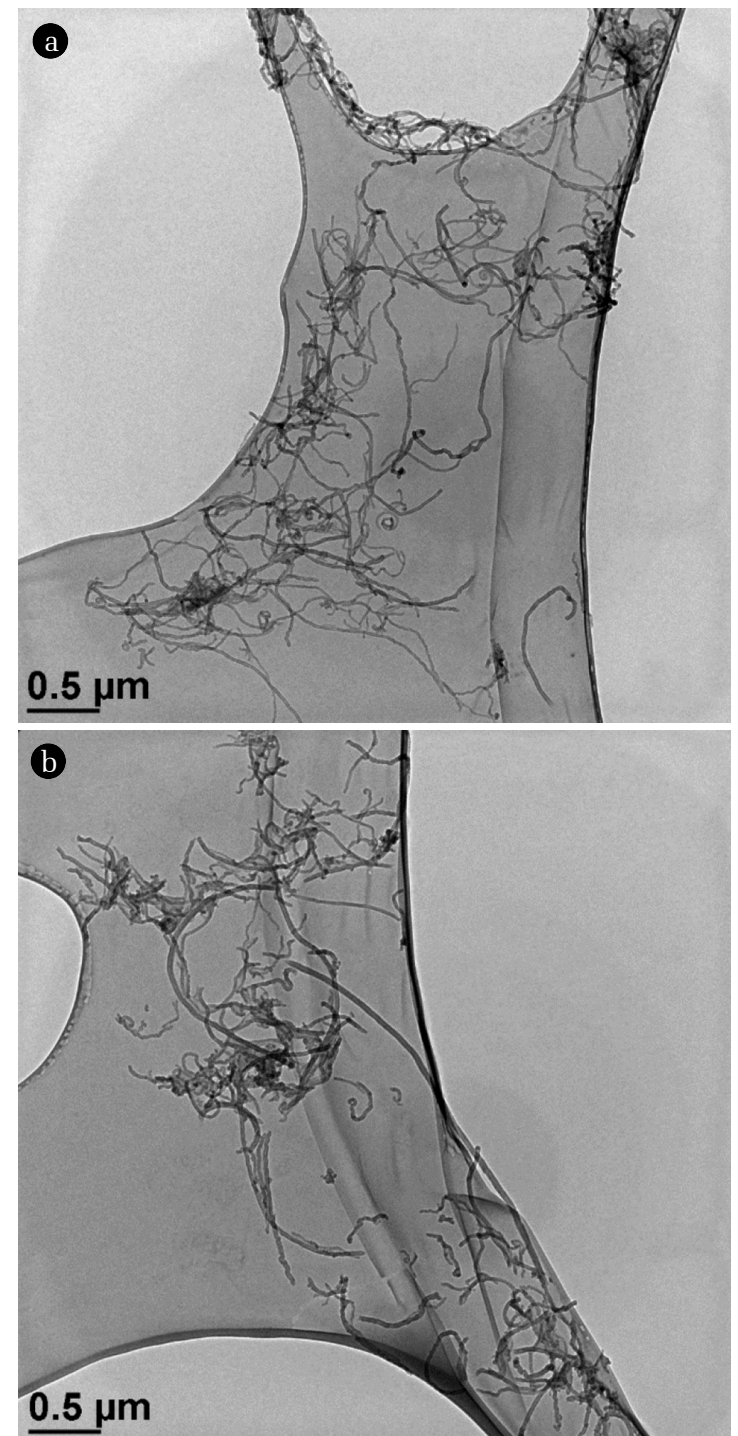

Fig. 2. TEM images of raw CNT (a) and functionalized CNT (b)

FTIR spectra of the CNTs are given in Fig. 3. Even though there are three main peaks $\left(\sim 3,440 \mathrm{~cm}^{-1}, \sim 1,630 \mathrm{~cm}^{-1}\right.$, and $\sim 1,560$ $\mathrm{cm}^{-1}$ ) on raw CNTs (Fig. 3(a)), there are very clear five peaks $\left(\sim 3,440 \mathrm{~cm}^{-1}, \sim 1,710 \mathrm{~cm}^{-1}, \sim 1,630 \mathrm{~cm}^{-1}, \sim 1,560 \mathrm{~cm}^{-1}\right.$, and $\sim 1,180 \mathrm{~cm}^{-1}$ ) on functionalized CNTs (Fig. 3(b)). The common peaks on both raw and functionalized CNTs that are $\sim 3,440$ $\mathrm{cm}^{-1}, \sim 1,630 \mathrm{~cm}^{-1}$, and $\sim 1,560 \mathrm{~cm}^{-1}$ correspond to adsorbed water [37-40], hydroxyl groups [39, 40] and carbon skeleton [40, 41], respectively. The new peaks appeared on functionalized CNTs, which are $\sim 1,710 \mathrm{~cm}^{-1}$ and $\sim 1,180 \mathrm{~cm}^{-1}$ correspond to $\mathrm{CNT}-\mathrm{COOH}$ [37-40].

To date, several authors demonstrate the functionalization of CNTs in a strong acid mixture. For instance, Choi et al. [16], Vatanpour et al. [42], and Norouzi et al. [43] functionalized CNTs in $\mathrm{HNO}_{3} / \mathrm{H}_{2} \mathrm{SO}_{4}=1 / 3$. They observed $1,430 \mathrm{~cm}^{-1}, 1,520 \mathrm{~cm}^{-1}, 1,680$ $\mathrm{cm}^{-1}, 1,715 \mathrm{~cm}^{-1}, 2,857-2,970 \mathrm{~cm}^{-1}, 3,435 \mathrm{~cm}^{-1}$ peaks that correspond to $\mathrm{COOH}, \mathrm{C}-\mathrm{C}, \mathrm{C}-\mathrm{O}, \mathrm{C}=\mathrm{O}, \mathrm{C}-\mathrm{H}$, and $-\mathrm{OH}$ functional groups, 


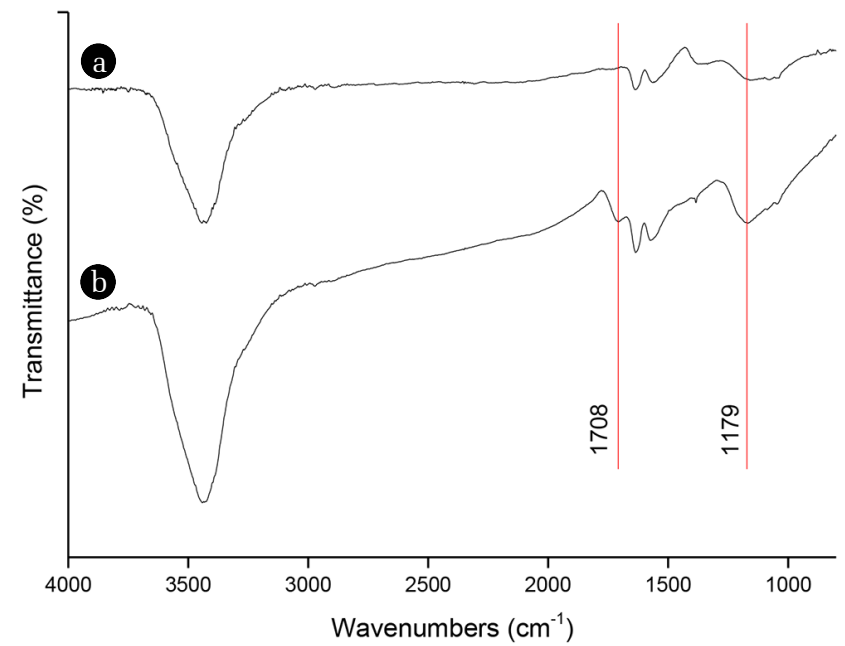

Fig. 3. FTIR spectra of the raw CNT (a) and functionalized CNT (b).

respectively with FTIR analysis of functionalized CNTs. Celik et al. [19, 20], and Celik Madenli and Cakmakci [27] functionalized CNTs in $\mathrm{HNO}_{3} / \mathrm{H}_{2} \mathrm{SO}_{4}=3 / 1$. Celik et al. [20] showed that the length of the CNTs were 1 3.5 $\mu \mathrm{m}$ before acid treatment and 50-800 nm after acid treatment, and Celik Madenli and Cakmakci [27] showed that the length of the CNTs were $\sim 10 \mu \mathrm{m}$ before acid treatment and $500 \mathrm{~nm}$ after acid treatment. Moreover, in their studies, they observed peaks on functionalized CNTs at $3,440 \mathrm{~cm}^{-1}$, $1,630 \mathrm{~cm}^{-1}, 1,460 \mathrm{~cm}^{-1}$, and $1,380 \mathrm{~cm}^{-1}$ correspond to $-\mathrm{OH}, \mathrm{C}=\mathrm{O}$, $\mathrm{O}-\mathrm{C}=\mathrm{O}$ and $-\mathrm{COOH}$, respectively with FTIR analysis of functionalized CNTs. As a result, the lengths of the CNTs are tens of micrometers before $\mathrm{H}_{2} \mathrm{SO}_{4}: \mathrm{HNO}_{3}$ treatment but shortened to hundreds of nanometers after $\mathrm{H}_{2} \mathrm{SO}_{4}: \mathrm{HNO}_{3}$ treatment. In addition, carboxylic groups were observed after the $\mathrm{H}_{2} \mathrm{SO}_{4}: \mathrm{HNO}_{3}$ treatment. Consistent with the previous research, TEM and FTIR results show that through a strong acid mixture treatment, CNTs were broken into smaller CNTs, tips were open, and carboxylic groups at the tips and the defect sites of the CNTs. These results verify the successful functionalization of the CNTs.

\subsection{Membrane Characterization}

Membrane performance strongly depends on surface chemistry [44]. Macromolecules tend to accumulate on the surface of the membranes because of the hydrophobic regions [45]. Membrane fouling can be reduced by increasing membrane hydrophilicity [46]. Membrane hydrophilicity can be investigated by measuring contact angles of membranes. The contact angle data of the fabricated membranes are displayed in Fig. 4. The membrane hydrophilicity improved with increasing CNT amount in polymer solution for all membranes because of the presence of functionalized CNTs containing carboxylic groups. However, changing the PES amount in the polymer solution did not induce statistically significant differences in the contact angles of fabricated membranes (by ANOVA tests). Hence, membrane hydrophilicity raised with increasing CNT amount, but it was not dependent on the PES amount.

The effect of polymer and CNT amounts on the porosity and mean pore diameter of the membranes are given in Table 1 . While

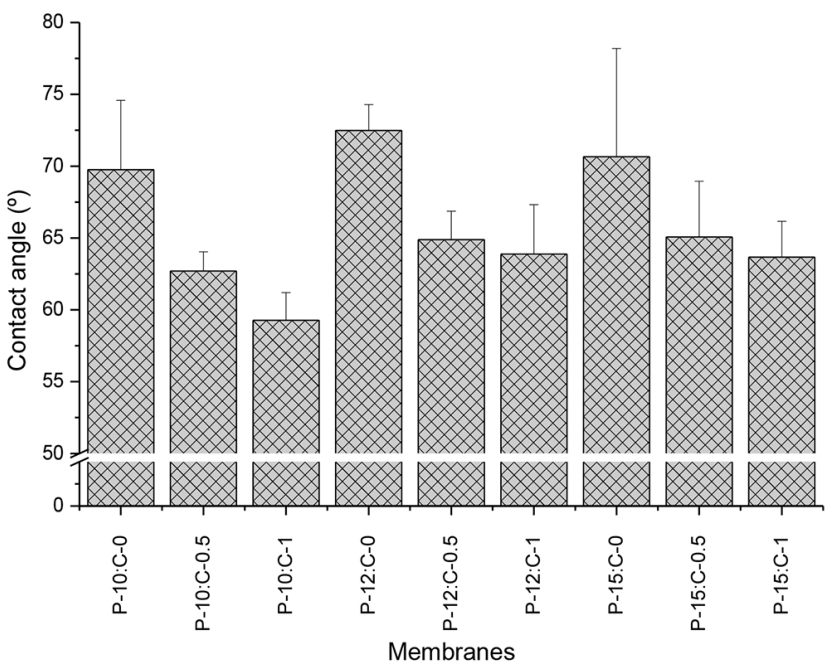

Fig. 4. Contact angles of the fabricated membranes.

Table 1. Porosity and Mean Pore Size of the Membranes

\begin{tabular}{lcc}
\hline Membrane & $\varepsilon$ & $\mathbf{R}_{\mathbf{m}}(\boldsymbol{\mu m})$ \\
\hline$P-10: C-0$ & 0.304 & 0.116 \\
$P-10: C-0.5$ & 0.356 & 0.098 \\
$P-10: C-1$ & 0.388 & 0.079 \\
$P-12: C-0$ & 0.301 & 0.115 \\
$P-12: C-0.5$ & 0.317 & 0.083 \\
$P-12: C-1$ & 0.383 & 0.076 \\
$P-15: C-0$ & 0.272 & 0.049 \\
$P-15: C-0.5$ & 0.298 & 0.043 \\
$P-15: C-1$ & 0.316 & 0.041 \\
\hline
\end{tabular}

the porosity decreased with increasing PES amount in the polymer solution, it increased with increasing the CNT amount in the polymer solution. Higher polymer concentration results in a lower porosity [1]. Pore sizes of the fabricated membranes reduced with increasing the CNT amount or PES amount in the polymer solution. In other words, the porosity is directly proportional to the CNT amount in the polymer solution, while the pore size is inversely proportional. This result can be explained by the delayed phase separation because of the enhanced casting solution viscosity by increasing polymer and CNT amount [19, 47].

\subsection{Membrane Permeability and Selectivity}

A decrease in flux is observed in polymeric membranes due to the compression of the pores with applied pressure, which is called membrane compaction. It is very common in pressure-driven membrane processes. When the membrane is compacted, steady-state performance is achieved [48]. As shown in Fig. 5, membrane compaction was achieved in $2 \mathrm{~h}$ of water filtration for all membranes. The permeability of the PES membranes is high because of its polarity and hydrophilicity [49]. Pure water flux decreased with increasing PES amount, which is consistent with the pore diameters of the membranes. The smaller pores resulted in reduced pure water flux. Higher polymer concentration results in lower porosity 
and flux [1]. Consistent with the membrane pore size, the pure water flux decreased with a $0.5 \%$ CNT addition in the polymer solution. Even though the pore size reduced with $1 \%$ CNT addition, the pure water flux increased, probably because of the enhanced hydrophilicity and porosity of the membranes by CNT addition. Membrane flux strongly depends on the overall porosity and the top surface properties of a membrane [16, 50, 51].

One of the typical pollutants found in water treatment is protein-like substances [9, 52], which cause severe fouling during membrane filtration [52-55]. BSA was used as a model protein for determining the selectivity and fouling resistance. All membranes were subjected to filtration using $1 \mathrm{~g} / \mathrm{L}$ BSA after $2 \mathrm{~h}$ of compaction, and the protein fluxes of the membranes were calculated using Eq. (4). The protein flux of the P-10:C-0, P12:C-0, and P15:C-0 at the end of $1 \mathrm{~h}$ BSA filtration were $78 \mathrm{~L} / \mathrm{m}^{2} \mathrm{~h}, 29 \mathrm{~L} / \mathrm{m}^{2} \mathrm{~h}$, and $14 \mathrm{~L} / \mathrm{m}^{2} \mathrm{~h}$, respectively. Consistent with the pore sizes and pure water flux of the membranes, the protein flux of the membranes

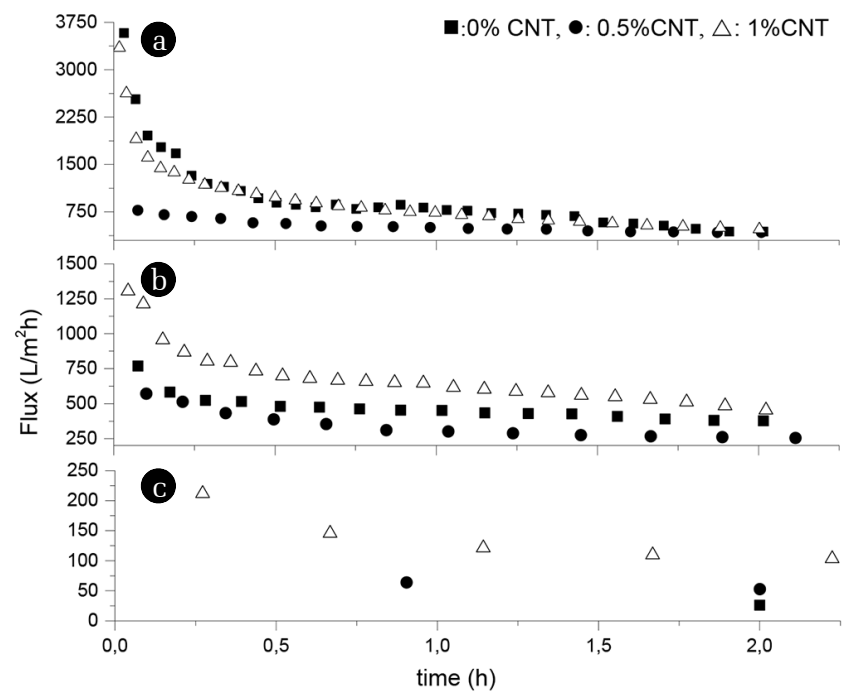

Fig. 5. Pure water fluxes of the membranes (a) 10\% PES, (b) $12 \%$ PES, (c) $15 \%$ PES.

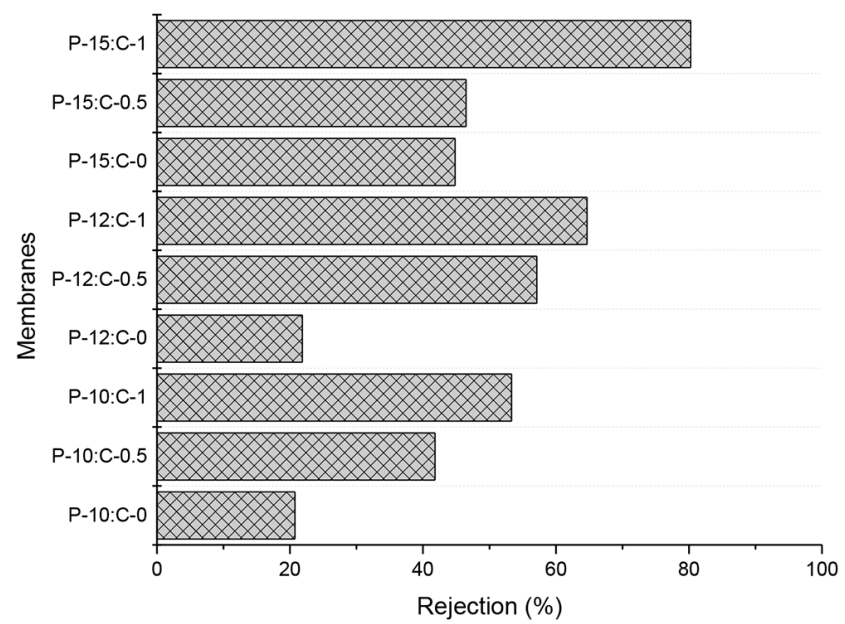

Fig. 6. BSA rejection of fabricated membranes.
Table 2. Hydraulic Resistances of the Fabricated Membranes

\begin{tabular}{lcc}
\hline Membrane & $\mathbf{R}_{\mathrm{vm}}\left(\times \mathbf{1 0}^{\mathbf{1 2}} \mathbf{~ m}^{-\mathbf{1}}\right)$ & $\mathbf{R}_{\mathrm{fm}}\left(\times \mathbf{1 0}^{\mathbf{1 2}} \mathbf{~ m}^{-\mathbf{1}}\right)$ \\
\hline$P-10: C-0$ & 0.385 & 2.283 \\
P-10:C-0.5 & 0.469 & 6.091 \\
P-10:C-1 & 0.390 & 4.687 \\
P-12:C-0 & 0.471 & 6.425 \\
P-12:C-0.5 & 0.790 & 9.586 \\
P-12:C-1 & 0.443 & 4.784 \\
P-15:C-0 & 3.125 & 12.728 \\
P-15:C-0.5 & 3.233 & 15.027 \\
P-15:C-1 & 2.517 & 10.815
\end{tabular}

decreased with increasing polymer amount. The protein flux of the P-10:C-1, P12:C-1, and P15:C-1 at the end of $1 \mathrm{~h}$ BSA filtration were $35 \mathrm{~L} / \mathrm{m}^{2} \mathrm{~h}, 45 \mathrm{~L} / \mathrm{m}^{2} \mathrm{~h}$, and $17 \mathrm{~L} / \mathrm{m}^{2} \mathrm{~h}$, respectively. Over $75 \%$ of pure water flux was lost at the end of $1 \mathrm{~h}$ BSA filtration in almost all membranes.

The protein rejections of the fabricated membranes are illustrated in Fig. 6. BSA rejections of the fabricated membranes increased with increasing PES or increasing CNT amount in the polymer solution. The smaller pores resulted in increased rejections.

Hydraulic resistances (Table 2) of the membranes were examined to determine the fouling behaviors of the membranes. Hydraulic resistance develops in the virgin membranes $\left(\mathrm{R}_{\mathrm{vm}}\right)$ due to the porosity, pore diameter, and cross-sectional framework. Hydraulic resistance of the membranes after filtration $\left(\mathrm{R}_{\mathrm{fm}}\right)$ occurs because of fouling and concentration polarization [28, 56]. The hydraulic resistance of the membranes increased with $0.5 \%$ CNT addition in the polymer solution, but reduced with 1\% CNT addition. That is, the fouling resistance of the membranes enhanced with increasing CNT amount in the polymer solution. Besides, increasing the PES amount in the polymer solution increased the hydraulic resistance of the membranes. The increased hydraulic resistance by increased PES amount might be because of the concentration polarization layer because of the increasing rejections. When high rejection with high flux is combined in the membrane operation, concentration polarization occurs. Hence concentration polarization is more severe in microfiltration and ultrafiltration operations [57, 58].

Considering the hydrophilicity, flux, porosity, and BSA rejection of the membranes, P-10:C-0, and P-12:C-0, showed quite similar properties. As a result, a $2 \%$ polymer difference did not result in a noteworthy difference in membrane properties. However, the P-15 membrane showed smaller pores, lower flux, higher BSA rejection than P-10:C-0 and P-12:C-0 membranes. Furthermore, CNT addition increased the hydrophilicity, flux, porosity, and BSA rejection in membranes with different polymer concentrations. CNT addition resulted in membranes with better membrane properties for all polymer concentrations.

\section{Conclusions}

Membranes with different polymer and CNT amounts were fabricated by the phase inversion method. Prior to fabrication, CNT functionalization was applied. TEM images and FTIR analysis of 
CNTs showed that the CNTs were shortened, the carbons at the defect sites, and the tips of the CNTs were converted to carboxylic groups.

There was more than a $10 \%$ increase in the hydrophilicity of the membranes with $1 \%$ CNT addition, but it was not altered with the polymer amount. Even though the porosity was increased $16 \%$ in P-15:C-1 compared to P-15:C-0, it was increased almost $30 \%$ in P-10:C-1 and P12:C-1 compared to P-10:C-0 and P12:C-0. The flux of P-15:C-1 is four times higher than P15:C-0. Moreover, the flux of the membranes reduced with increasing polymer amount (denser membrane structure) due to the reduced porosity. Consistent with the pore sizes of the membranes, BSA rejection enhanced with increasing polymer or CNT amount in the polymer solution. Besides, fouling resistance of the membranes decreased with increasing polymer amount but increased with increasing CNT amount because the concentration polarization and the hydraulic resistance of the membranes reduced with increasing CNT amount. That is, increasing the CNT amount in the polymer solution increased fouling resistances of the membranes, which is consistent with our previous findings. Membranes prepared with a higher amount of polymer concentrations are more prone to membrane property improvements by CNT addition. The increase in flux and selectivity by CNT addition for all polymer concentrations will increase the membrane life-time and reduce the treatment cost. A fundamental understanding of the effects of the polymer and CNT amount on the membranes can be achieved with this work.

\section{Acknowledgment}

Funding was provided by the Scientific and Technological Research Council of Turkey (Project No. 111R012) and Suleyman Demirel University (Project No. SDU-3785)

\section{Author Contributions}

E.C.M. (Assoc. Prof.) has supervised the study, prepared the figures and tables, written and revised the manuscript several times, and Z.I.C. (Master student) has conducted all the experiments.

\section{References}

1. Mulder M. Basic principles of membrane technology. 2nd ed. The Netherlands: Kluwer Academic Publishers 1997.

2. Baker RW Membrane technology and applications. 2nd ed. England: McGraw-Hill 2004.

3. Idris A, Ahmed I. A production of Polyethersulfone Asymmetric Membranes Using Mixture of Two Solvents and Lithium Chloride as Additive. In: 1st International Conference on Natural Resources Engineering \& Technology; 24-25 July 2006; Putrajaya, Malaysia. p. 408-415.

4. Peng FB, Hu CL, Jiang ZY. Novel ploy(vinyl alcohol)/carbon nanotube hybrid membranes for pervaporation separation of benzene/cyclohexane mixtures. J. Membr. Sci. 2007;297:236-242.

5. Yang YN, Zhang HX, Wang P, Zheng QZ, Li J. The influence of nano-sized $\mathrm{TiO}_{2}$ fillers on the morphologies and properties of PSFUF membrane. J. Membr. Sci. 2007;288:231-238

6. Park S, Yang E, Park H, Choi H. Fabrication of functionalized halloysite nanotube blended ultrafiltration membranes for high flux and fouling resistance. Environ. Eng. Res. 2020;25:771-778.

7. Iijima S. Helical microtubules of graphitic carbon. Nature 1991;354:56-58.

8. Bui TX, Choi H. Nanoscale carbon materials for contaminant separation. In: Zhang TC, Hu Z, Surampalli RY, Tyagi RD, Lai K.C.K, Lon I.M.C, eds. Nanotechnologies for Water Environment Applications. USA: American Society of Civil Engineers, 2009. p. 269-311.

9. Liu X, Wang M, Zhang S, Pan,B. Application Potential of Carbon Nanotubes in Water Treatment: A Review. J. Environ. Sci. (China) 2013;25:1263-1280.

10. Noorimotlagh Z, Mirzaee SA, Martinez SS, Alavi S, Ahmadi $\mathrm{M}$, Jaafarzadeh N. Adsorption of textile dye in activated carbons prepared from DVD and CD wastes modified with multi-wall carbon nanotubes: Equilibrium isotherms, kinetics and thermodynamic study. Chem. Eng. Res. Des. 2019;141:290-301.

11. Salam MA, Mohamed RM. Removal of antimony (III) by multi-walled carbon nanotubes from model solution and environmental samples. Chem. Eng. Res. Des. 2013;91:1352-1360.

12. Li Y, Dua Q, Liu T, et al. Comparative study of methylene blue dye adsorption onto activated carbon, graphene oxide, and carbon nanotubes. Chem. Eng. Res. Des. 2013;91:361-368.

13. Kar S, Bindal RC, Tewari PK Carbon Nanotube Membranes for Desalination and Water Purification: Challenges and Opportunities. Nano Today 2012;7:385-389.

14. Goh PS, Ismail AF, Ng BC. Carbon Nanotubes for Desalination: Performance Evaluation and Current Hurdles. Desalination 2013;308:2-14.

15. Qu X, Alvarez PJJ, Li Q. Applications of Nanotechnology in Water and Wastewater Treatment. Water Res. 2013;47:39313946.

16. Choi JH, Jegal J, Kim WN. Fabrication and characterizationof multi-walled carbon nanotubes/polymer blend membranes. J. Membr. Sci. 2006;284:406-415

17. Qiu S, Wu LG, Pan XJ, ZhangnL, Chen HL, Gao CJ. Preparation and properties of functionalized carbon nanotube/PSF blend ultrafiltration membranes. J. Membr. Sci. 2009;342:165-172

18. Nechifor G, Voicu SI, Nechifor AC, Garea S. Nanostructured hybrid membrane polysulfone-carbon nanotubes for hemodialysis. Desalination 2009;241:342-348.

19. Celik E, Park H, Choi H, Choi H. Carbon Nanotubes Blended Polyethersulfone Membranes for Fouling Control in Water Treatment. Water Res. 2011;45:274-282.

20. Celik E, Liu L, Choi H. Protein Fouling Behavior of Carbon Nanotube/Polyethersulfone Composite Membranes During Water Filtration. Water Res. 2011;45:5287-5294.

21. Zhao H, Qiu S, Wu L, Zhang L, Chen H, Gao C. Improving the performance of polyamide reverse osmosis membrane by incorporation of modified multi-walled carbon nanotubes. J. Membr. Sci. 2014;450:249-256.

22. Kim HJ, Choi K, Baek Y, Kim DG, Jimin S, Yoon J, Lee JC. 
High-Performance Reverse Osmosis CNT/Polyamide Nanocomposite Membrane by Controlled Interfacial Interactions. ACS Appl. Mater. Interfaces 2014;6:2819-2829.

23. Wang L, Song X, Wang T, Wang S, Wang Z, Gao C. Fabrication and characterization of polyethersulfone/carbon nanotubes (PES/CNTs) based mixed matrix membranes (MMMs) for nanofiltration application. Appl. Surf. Sci. 2015;330:118-125.

24. Yang Y, Nie C, Deng Y, Cheng C, He C, Ma L, Zhao C. Improved antifouling and antimicrobial efficiency of ultrafiltration membranes with functional carbon nanotubes. RSC Adv. 2016;6:88265-88276.

25. Celik Madenli E, Yanar N, Choi H. Enhanced antibacterial properties and suppressed biofilm growth on multi-walled carbon nanotube (MWCNT) blended polyethersulfone (PES) membranes. J. Environ. Chem. Eng. 2021;9:104755.

26. Choi H, Yoon SH, Son M, Celik E, Park H, Choi H. Efficacy of synthesis conditions on functionalized carbon nanotube blended cellulose acetate membrane for desalination. Desalin. Water Treat. 2016;57:7545-7554.

27. Celik Madenli E, Cakmakci O. Preparation and characterization of PAN/CNT nanocomposite fiber supports for membrane filtration. Desalin. Water Treat. 2017;60:137-143

28. Celik Madenli E, Cakmakcı O, Isguder I, et al. Effects of the solvent ratio on carbon nanotube blended polymeric membranes. In: Figoli A, Hoinkis J, Altinkaya SA, Bundschuh J, eds. Application of Nanotechnology in Membranes for Water Treatment. London: CRC Press; 2017. p. 111-127.

29. Liu L, Son M, Park H, Celik E, Bhattacharjee C, Choi H. Efficacy of CNT-bound polyelectrolyte membrane by spray-assisted layer-by-layer (LbL) technique on water purification, RSC Adv. 2014;4:32858-32865.

30. Li J, Xu Z, Yang H, Yu L, Liu M. Effect of $\mathrm{TiO}_{2}$ nanoparticles on the surface morphology and performance of microporous PES membrane. Appl. Surf. Sci. 2009;255:4725-4732

31. Rajesh S, Shobana KH, Anitharaj S, Mohan DR. Preparation, Morphology, Performance, and Hydrophilicity Studies of Poly(amide-imide) Incorporated Cellulose Acetate Ultrafiltration Membranes. Ind. Eng. Chem. Res. 2011;50:5550-5564.

32. Wu G, Gan S, Cui L, Xu Y. Preparation and characterization of $\mathrm{PES} / \mathrm{TiO}_{2}$ composite membranes. Appl. Surf. Sci. 2008;254: 7080-7086.

33. Nakamura K, Matsumoto K. Properties of protein adsorption onto pore surface during microfiltration: Effects of solution environment and membrane hydrophobicity. J. Membr. Sci. 2006;280:363-374.

34. Zhu J, Kim JD, Peng HQ, Margrave J, Khabashesku VN, Barrera EV. Improving the dispersion and integration of single-walled carbon nanotubes in epoxy composites through functionalization. Nano Lett. 2003;3:1107-1113.

35. Maser W, Benito AM, Munoz E, Martinez MT. Carbon nanotubes: from fundamental nanoscale objects towards functional nanocomposites and applications. In: Vaseashta A, Mihailescu IN, eds. Functionalized nanoscale materials, devices and systems. NATO science for peace and security series-B: Physics and biophysics. The Netherlands: Springer; 2008. p.101-119.

36. Hirsch A, Vostrowsky O. Functionalization of carbon nanotubes. In: Schlüter AD, eds. Functional Molecular Nanostructures.
Topics in Current Chemistry. Berlin: Springer; 2005. p. 193-237. 37. Escobar Barrios VA, Rangel Mendez JRR, Perez Aguilar NV, Espinosa GA, Davila Rodriguez JL. FTIR - An Essential Characterization Technique for Polymeric Materials. In: Theophile T, eds. Infrared Spectroscopy-Materials Science, Engineering and Technology. Croatia: InTech; 2012. p. 195-212.

38. Baykal A, Senel M, Unal B, Karaoglu E, Sozeri H, Toprak MS. Acid Functionalized Multiwall Carbon Nanotube/Magnetite (MWCNT)-COOH/ $/ \mathrm{Fe}_{3} \mathrm{O}_{4}$ Hybrid: Synthesis, Characterization and Conductivity Evaluation. J. Inorg. Organomet. Polym. Mater. 2013;23:726-735.

39. Mansor NBA, Tessonnier JP, Rinaldi A, Reiche S, Kutty MG. Chemically Modified Multi-Walled Carbon Nanotubes (Mwcnts) with Anchored Acidic Groups. Sains Malays. 2012;41: 603-609.

40. Tucureanu V, Matei A, Avram AM. FTIR Spectroscopy for Carbon Family Study, Crit. Rev. Anal. Chem. 2016;46:502-520.

41. Seo DW, Yoon WJ, Park SJ, Jo MC, Kim JS. The Preparation of Multi-walled CNT-PMMA Nanocomposite. Carbon Lett. 2006; 7:266-270.

42. Vatanpour V, Madaeni SS, Moradian R, Zinadini S, Astinchap B. Fabrication and Characterization of Novel Antifouling Nanofiltration Membrane Prepared from Oxidized Multiwalled Carbon Nanotube/Polyethersulfone Nanocomposite. J. Membr. Sci. 211;375:284-294

43. Norouzi M, Pakizeh M, Namvar-Mahboub M. The Effect of highly dispersed oxidized multi-walled carbon nanotubes on the performance of PVDF/PVC ultrafiltration membrane Desalin. Water Treat. 2016;57:24778-24787

44. Reddy A.V.R, Patel HR. Chemically treated polyethersulfone/polyacrylonitrile blend ultrafiltration membranes for better fouling resistance. Desalination 2008;221:318-323.

45. Blanco JF, Sublet J, Nguyen QT, Schaetzel P. Formation and morphology studies of different polysulfones-based membranes made by wet phase inversion process. J. Membr. Sci. 2006;283: 27-37.

46. Wang YQ, Su YL, Sun Q, Ma X工, Jiang ZY. Generation of anti-biofouling ultrafiltration membrane surface by blending novel branched amphiphilic polymers with polyethersulfone. J. Membr. Sci. 2006;286:228-236.

47. Han MJ, Nam ST. Thermodynamic and rheological variation in polysulfone solution by PVP and its effect in the preparation of phase inversion membrane. J. Membr. Sci. 2002;202:55-61.

48. Volkov A. Membrane Compaction. In: Drioli E, Giorno L eds. Encyclopedia of Membranes. Springer, Berlin, Heidelberg; 2016. p. 35-60.

49. Son M, Choi H, Liu L, Choi H. Optimized Synthesis Conditions of Polyethersulfone Support Layer for Enhanced Water Flux for Thin Film Composite Membrane. Environ. Eng. Res. 2014;19:339-334.

50. Silva TLS, Morales-Torres S, Figueiredo JL, Silva AMT. Multi-walled carbon nanotube/PVDF blended membranes with sponge- and finger-like pores for direct contact membrane distillation. Desalination 2015;357:233-245.

51. Xu L, He J, Yu Y, Chen JP. Effect of CNT content on physicochemical properties and performance of CNT composite polysulfone membranes. Chem. Eng. Res. Des. 2017;121:92-98. 
52. Ding Y, Ma B, Liu H, Qu J. Effects of protein properties on ultrafiltration membrane fouling performance in water treatment. J. Environ. Sci. (China) 2019;77:273-281.

53. Ma BW, Yu WZ, Liu HJ, Yao JB, Qu JH. Effect of iron aluminum hydrolyzed precipitate layer on ultrafiltration membrane. Desalination 2013;330:16-21.

54. Huner ID, Gulec HA. Fouling behavior of poly(ether) sulfone ultrafiltration membrane during concentration of whey proteins: effect of hydrophilic modification using atmo-spheric pressure argon jet plasma. Colloids Surf. B 2017;160:510-519.

55. Vanangarnudi A, Dumee LF, Duke MC, Yang X. Nanofiber composite membrane with intrinsic Janus surface for reversed- protein-fouling ultrafiltration. ACS Appl. Mater. Interfaces 2017;9:
18328-18337.

56. Huang ZQ, Chen K, Li SN, Yin XT, Zhang Z, Xu HT. Effect of ferrosoferric oxide content on the performances of polysulfone-ferrosoferric oxide ultrafiltration membranes. J. Membr. Sci. 2008;315:164-171

57. Celik E, Choi H. Carbon Nanotube/Polyethersulfone Composite Membranes for Water Filtration. In: Escobar I, Bruggeb BVd, eds. Modern Applications in Membrane Science and Technology. Washington DC: ACS Symposium Series, American Chemical Society; 2011. p. 257-269.

58. Vankelecom IFJ, Gevers LEM. Membrane processes. In: Afonso A M, Crespo JG, eds. Green separation processes: Fundamentals and applications. Germany: Wiley W.C.H.; 2005. p. 251-270. 